\title{
The Pictures in Our Heads
}

\section{Jennifer Kowalewski, Georgia Southern University, USA}

\begin{abstract}
s
Most research has focused on how conventional news influenced second-level agenda setting, but more research needs to investigate how humorous news might affect attribute agenda setting, and compare those effects with conventional news. In this experiment, participants received media messages with the same information structured as either conventional news or humorous news to examine how the structure of the media message might affect second-level agenda setting. The results indicated people accepted the attributes of issues related to certain issues when it was presented as a humorous news program. However, conventional news was more successful in second-level agenda setting as compared to humorous news, meaning people accepted attributes of issues more when presented as a conventional news program.
\end{abstract}

Keywords: Attribute Agenda Setting, Humorous News, Conventional News, Experiment "The Pictures in Our Heads": How Conventional News Versus Humorous News Might Influence the Transfer of Issue Attributes from the Media's Agenda to the Public's Agenda 
Walter Lippmann (1922) first theorized the media created "the pictures in our heads." Scholars through the years have found support for this idea that the media could affect public opinion formation by focusing on certain issues and attributes of issues that are transferred from the media's agenda to the public's agenda. With a myriad of studies, scholars have shown how conventional news could affect second-level agenda setting by making attributes of issues more salient in people's minds (McCombs, 2004). However, conventional news no longer has a monopoly on informing the populace. Survey research has shown how young people turn to humorous news shows for information (Kohut, 2007). These shows use satire to present information; however, people gain political information from these shows. Therefore, these shows could sway public opinion formation.

Pew Research Center has shown those that watch humorous programs, like The Daily Show with Jon Stewart or The Colbert Report with Stephen Colbert, have political knowledge. However, the 2012 survey could not determine if the shows led to people having more political knowledge, because they had to have political knowledge to understand the jokes, or did the people have more political knowledge because of the shows. Scholars have answered this question, by showing that people could learn from humorous shows (Young \& Hoffman, 2009). If they learn from these programs, could they also learn about the relative importance of attributes as well?

The present study was designed to determine this by focusing on whether humorous news shows affect the transfer of attributes associated with issues and, if so, whether the shows affect the transfer of attribute salience similarly to conventional news shows. Through creating stimulus material, this experimental study compared conventional news, such as what one might hear on CNN, with humorous news, such as what one might hear on The Daily Show or The Colbert Report, to determine how either impacted second-level agenda-setting effects.

\section{Literature Review}

Research into agenda setting has continued since McCombs and Shaw's seminal study of the 1968 presidential election (1972). The results indicated the media do have an influence on the salience of certain issues in the public arena. This became known as object agenda setting, or 
first-level agenda setting, as this level of agenda setting speaks to whether the frequency and prominence regarding how a general issue is covered in the media will impact how important the public views that issue, irrespective of how the issue is covered.

Examinations of elements of an issue, rather than salience of issues as a whole, describes what Wanta and Ghanem (2007) defined as second-level agenda setting. Regarding the first level of agenda setting, research concentrates on how frequently and prominently the news media cover issues. Regarding the second level of agenda setting, research concentrates on how the news media report on attributes prevalent within those issues or other "objects" in the news. Alternatively, if news media focus on certain attributes of issues, citizens use those attributes more when thinking about those issues (McCombs, 2004). For example, when the news media focus on personal characteristics of a politician, citizens reference those personal characteristics when they think about that politician. If the attributes are presented as negative in news stories, citizens may think negatively about the politician.

Overall, a myriad of studies have shown citizens not only use the conventional news media to determine what issues are the most important, but they also use the conventional news media to determine what attributes of issues are the most imperative to consider when thinking about that issue (McCombs, Llama, Lopez-Escobar, \& Rey, 1997; McCombs, Llama, \& Lopez-Escobar, 2000). Because agenda setting should occur similarly regardless of the issue, the current study investigated agenda-setting effects with three different issues. Participants received only one of the three issues (health care, immigration, or offshore drilling). Then, the study compared the number of attributes accepted about issues compared with people in the other two conditions as the control group. This study hypothesized similar results to agenda-setting studies by focusing on how many attributes participants cited from the issues they received compared to the control group.

H1: Participants who received a conventional news story about one of three issues (health care, immigration, or offshore drilling) will discuss the attributes of that issue significantly more as compared to the control group. 


\section{Humorous News Programs}

Research has shown how structures of information, such as news photographs, could affect the transfer of issue and attribute salience from the media's agenda to citizens' agendas (Wanta, 1988). In regards to humorous news programs specifically, scholars have shown influence on first-level agenda setting in that humorous news programs transferred the salience of certain issues from the media's agenda to the citizens' agenda (Kowalewski, 2013; Kowalewski, 2013; Kowalewski \& Stewart, 2013). However, scholars have not investigated how these humorous programs might relate to the second-level agenda-setting effects. Instead of considering only agenda-setting studies, the study examined another theory closely aligned with agenda setting, especially second-level agenda setting - priming, which relates to how one stimuli or event might trigger future evaluation of related stimulus or events through the network model of memory (Roskos-Ewoldson, Klinger \& Roskos-Ewoldson, 2007). Iyengar and Kinder (1986; 1987) defined political priming in terms of when the news media focus on certain issues; citizens use those certain issues in their evaluation of political leaders or events. For example, when the news media focus on the economy, citizens will evaluate the president on how well or how poorly he is handling the economy. Research, though, has shown that conventional news media are not alone in priming citizens in their overall evaluations of subsequent stimulus (Moy, Xenos $\&$ Hess, 2005).

Scholars have shown how humorous news programs affect citizens' opinions toward political leaders. Moy et al. (2005) argued late-night comedy shows primed positive thoughts about presidential candidates in citizens' minds after those candidates appeared on such programs. Because of the effect these programs have on public opinion formation, citizens have seen a rise in more political candidates appearing on late-night comedy programs (Moy et al., 2005; Weaver, 1994). Often, candidates use humorous news shows to not only reach a different audience, but to appear more personable than they might appear to citizens while on the campaign trail or in conventional news. Richard Nixon was one of the first candidates to use

humorous shows when he appeared on Rowan \& Martin's Laugh-In prior to the 1968 presidential election. Show producer George Schlatter argued Nixon's appearance on the show made him look like "a nice guy" to voters, although no quantitative evidence exists to support his 
claim (Kolbert, 2004). Candidates, though, have increasingly turned to humorous news shows, such as when John Edwards announced his candidacy for president on The Daily Show in 2004. Overall, research has shown humorous news could influence public opinion formation. Although most studies have investigated this effect through priming research, this study hypothesized similar findings for second-level agenda-setting effects because often scholars have tied both theories together through the idea of accessibility (Miller \& Krosnick, 2000; Scheufele, 2000; Scheufele \& Tewksbury, 2007). By being accessible in memory, these attributes associated with these issues transfer from humorous news programs to citizens' agendas. Citizens are thus more likely to use these attributes when considering a subsequent stimulus. Therefore, the study hypothesized:

H2: Participants who received a humorous news story about one of three issues (health care, immigration, or offshore drilling) will discuss the attributes of that issue significantly more as compared to the control group.

\section{Conventional News versus Humorous News}

A major cognitive mechanism behind agenda setting relates to accessibility in that the more accessible an attribute is in memory, the more likely citizens would think about that attribute (Miller \& Krosnick, 2000; Scheufele \& Tewksbury, 2007). Although not a lot of scholars have investigated conventional news compared to humorous news with regards to agenda setting specifically, scholars have looked into how citizens react to serious messages versus humorous messages (Holbert, Hmielowski, Jain, Lather \& Morey, 2011; Holbert et al., 2013).

Holbert and his colleagues compared how citizens reacted to information presented satirical or not. These studies investigated how citizens reacted to messages presented as a typical opinion editorial, such as one might see in the news, or to messages presented as satirical. The scholars, however, understood not all satire was the same. The scholars investigated two types of satire horatian satire, defined by these scholars as light and witty, versus juvenalian satire, defined by these scholars as bitter and harsh. Their findings indicated citizens felt the horatian satire to have less message strength and less influence on self than the juvenilian satire and the opinion editorials (Holbert et al., 2011; Holbert et al., 2013). When investigating The Daily Show or The 
Colbert Report specifically, scholars have shown these programs influence citizens' perceptions (Polk, Young, \& Holbert, 2009; Holbert, Lambe, Dudo \& Carlton, 2007; Morris, 2009). Scholars have argued these shows specifically could influence everything from citizens' political knowledge and issue salience (Kowalewski, 2013; Kowalewski, 2013; Kowalewski \& Stewart, 2013) to perceptions on conventional news programs (Holbert et al., 2007). One study that investigated The Colbert Report's impact on young viewers argued that citizens failed to critically question messages in humorous form; therefore, citizens agree with those messages (Baumgartner \& Morris, 2006). By agreeing with the message, they might accept the message, meaning the message will more likely be accessible in memory and influence second-level agenda-setting effects.

But the comparisons between conventional news and humorous news may not be so simple. Other scholars have argued a difference exists between serious messages and humorous messages. Even though many citizens turn to humorous messages for enjoyment, citizens fail to accept the information in these programs containing humor as compared to those containing serious messages (Zillmann, 2000). Scholars argued citizens discount information if the information has humor embedded within it, making the information less influential (Nabi, Moyer-Guse \& Byrne, 2007). If the information is less influential, the information might not be as accessible in memory; therefore, the information might not have as much of an effect on citizens' acceptance of the agenda because they discount the humorous message. Conventional news might relate to agenda-setting effects more because citizens fail to discount the information, making the information more accessible in memory.

As shown by the previous literature, scholars have argued that humorous programs might or might not be more readily accepted by citizens. If citizens accept the information structured with humor embedded in it, the message might be more accessible in memory as compared to information structured in a more conventional way. However, if citizens fail to accept the information structured with humor in it, the message might be less accessible in memory than information structured in a more conventional way. Accessibility in memory is a key component 
to agenda setting. Therefore, since research has not determined which might be more accessible in memory, this study asked the research question:

RQ: Are participants more likely to adopt the attributes of an issue presented in a news story if that news story is conventional or if the news story is humorous?

\section{Method}

Although the process involving agenda setting may take time, scholars have used experimental design to show an agenda-setting effect (Iyengar \& Kinder, 1986; 1987; Wanta, 1988). In recent years, scholars have used experimental designs to determine mediating factors in agenda setting (Miller \& Krosnick, 2007). Therefore, this study used an experimental design to determine whether conventional or humorous news influenced second-level agenda-setting effects. Participants were randomly assigned to receive news stories structured as either conventional news or humorous news. Participants also were randomly assigned to receive one of three issue stories. To counteract any problems associated with the transfer of attribute salience associated with issues, the researcher used three different issues - health care, immigration, and offshore drilling - which were all prevalent within the media at the time of this study. Participants received only one of the three issue stories, as well as two buffer stories regarding abstinence-only programs and violent video games. The two buffer stories were used to mask the true nature of the study.

Participants were recruited from a private university in the south, as well as from the local community to obtain both older and younger participants $(n=192)$. Participants came to a computer lab where they were randomly assigned to different computers. They first answered demographic questions online, and then listened to a simulated radio address with one of the three issues embedded into it structured as either conventional news or humorous news. They listened to the radio address with headphones, so they did not know others had different versions of the radio addresses. Following exposure to the stimulus material, participants completed a Sudoku as a distraction before answering questions to gauge second-level agenda-setting effects. 
Most of the participants were female, $73.4 \%, n=141$. The study had a split between older participants (47.9\% were 25 and older) and younger participants $(52.1 \%$ were 18 to 24 years old), ranging in age from 18 to 84 . More than half of the participants indicated they were Republican $(53.1 \%, n=102)$ rather than Democrat $25.0 \%, n=48$.

\section{Stimulus Material}

Participants heard a radio address containing only one of three issue stories focusing on either the issues of health care, immigration, or offshore drilling. The researcher created stimulus material presented as a radio address; however, participants did not know about the fake nature of the radio address until the conclusion of the experiment. Participants were told a university in another state had begun this radio program, and the researcher was hired to determine reaction to the radio program. The deception was necessary to give legitimacy to the radio address and to mask the true nature of the study. The Institutional Review Board where the experiment was done approved the study.

The researcher used a radio address for this experiment to control for modality. The researcher paid a professional radio announcer from another state to do the radio address, so participants would not have prior knowledge of this person or his work. Hearing a radio address means the findings cannot specifically explain the impact of The Daily Show or The Colbert Report on people. However, the findings could help understand if participants accept humorous news similar to conventional news. The study controlled not only for modality, but for the information participants received to better compare the types of programs in general. Both versions of the radio address, the conventional news and the humorous news, had the exact same information. If the results show a difference between the two versions, the researcher can assume the changes are a result of whether the information was presented as conventional news or humorous news. Participants were randomly assigned to hear information either presented as conventional news or the humorous news. The stories on each topic contained the same information, but the humorous news contained humorous statements citizens might hear if they listened to programs such as The Daily Show. The statements were taken from humorous comments made on news programs such as The Daily Show, as well as the humorous fake-news website The Onion. The 
researcher looked at transcripts of The Daily Show and online at The Onion website, taking humorous comments made about topics related to health care, immigration, and offshore drilling to embed into the news stories. For example, in the immigration story, both versions discussed how America needed measures to stop illegal immigrants from entering the country; but a comment from The Onion was embedded into the humorous new story discussing how "Measures include frowning exercises to show those foreigners how unwelcoming America really is."

The stories regarding health care, immigration, and offshore drilling centered on a fictitious Senator in the U.S. Congress, who planned to propose a new law when he went to Washington, D.C. Those exposed to the health care story heard about the senator wanting to give incentives to companies to provide health care to decrease the number of people on Medicare. Participants who heard the immigration story heard information about the senator wanting to create a special organization to track down and to deport illegal immigrants. Those exposed to the offshore drilling story heard how the senator wanted to do more offshore drilling. Besides the issue story, participants heard two buffer stories so participants could not figure out the true nature of the study. Although the humorous radio addresses were slightly longer because of the humorous statements embedded within, the humorous news condition was at most 1 minute longer than the conventional radio address, with the radio addresses lasting from 5 to 6 minutes.

When citizens turn to humorous programs, they know they are receiving the information structured in a humorous way. To ensure citizens understood they would be listening to humorous news stories, the radio address began in a more humorous manner with the announcer stating "This is WSUR, Wyoming State University Radio. Of all the 24-hour radio streams out of Wyoming, we're one of them," rather than just identifying WSUR. This ensured that participants knew the issue story presented would be humorous in nature and came from a location outside of the participants' region. 


\section{Manipulation Check}

The researcher used an entertainment scale as a template to create measures to determine if those who received the humorous news viewed the information as more entertaining than the conventional news (Zillmann, Taylor \& Lewis, 1998). The entertainment scale averaged the five statements: It was amusing, hilarious, enjoyable, entertaining, made me laugh ( $\alpha=.93)$. Participants found the humorous news more entertaining than the conventional news for all three issues: health care humorous news $(M=6.58, S D=2.55)$, health care conventional news $(M=$ 3.94, $S D=1.90),(t(59)=4.60, p<.001)$; immigration humorous news $(M=5.82, S D=2.55)$, immigration conventional news $(M=3.24, S D=1.79),(t(68)=4.91, p<.001)$; and offshore drilling humorous news $(M=4.92, S D=2.40)$, offshore drilling conventional news $(M=2.65$, $S D=1.16), t(59)=4.68, p<.001$.

The researcher also asked participants the most important problem question to gauge the firstlevel agenda-setting effects. Participants were asked what three issues they considered the most important problem, regardless of what issue they were exposed to in the experiment. The MIP question has been used by other scholars to gauge first-level agenda-setting effects (McCombs, 2004). The open-ended MIP underwent Chi Square analysis. When participants were exposed to an issue in a news story, they cited the issue more as compared to those who did not receive the issue: health care $\chi^{2}(91)=7.96, p<.01$; immigration $\chi^{2}(35)=10.24, p<.001$; and offshore drilling $\chi^{2}(50)=18.31, p<.001$.

\section{Variables}

\section{Independent Variables}

Participants received either conventional news $(n=97)$ or humorous news $(n=95)$ presented as a simulated radio address. Participants also received only one of three issue stories -- health care $(n=61)$, immigration $(n=70)$, or offshore drilling $(n=61)$.

\section{Dependent Variables}

Scholars have gauged the salience of issue attributes by asking citizens "if they had to tell a friend about an issue, what would they tell their friend about that issue?"(McCombs, 2004). If 
citizens cite the attributes of the issue significantly more in their response, scholars have posited that showed a second-level agenda-setting effect. Similar to other studies into second-level agenda setting, the study counted the number of attributes the participants cited when they were asked what they would tell their friends because as other researchers have shown that equated more to message acceptance because citizens often would not tell their friends information they haven't cognitively processed. Therefore, this equated more to message acceptance than mere recall of the information. The method was similar to what was done in previous studies, including Althaus and Tewksbury (2002). In the study, the authors found that recall is important for issue salience, but the scholars went on to investigate the importance of issue salience and not merely recall of the issue. This study was similar in method, investigating what people remembered from the stories they heard; however, this study also investigated the issue importance the participants put on the issues they received through not only the open-ended measure, but several close-ended measures shown to gauge second-level agenda-setting effects.

To ensure that this was not merely recall but acceptance of the issues, the researcher used closedended measures of second-level agenda setting that scholars have shown gauge second-level agenda setting (Evatt, \& Ghanem, 2001). The open-ended measure correlated with the closeended measures. The close-ended measures included several semantic differential scales, asking participants to indicate their overall feelings toward the issue on an 11-point scale with variables reverse-coded so the higher number meant individuals felt the information more significant (interesting/not interesting; important/not important; irrelevant/relevant; does not matter to me; boring/not boring; exciting/not exciting; of concern to me/not of concern to me). Other measures of salience included an 11-point Likert scaling, so the higher number meant more agreement with statements about the information presented in the stories (the information was: informative; authentic; credible; seemed real to me; newsworthy; interesting; and boring). Because the openended measures and close-ended measures correlated significantly, the findings indicated the discussion of attributes in this measure was an agenda-setting effect, and not merely recall.

Also, participants completed a distraction before answering the questions. The distraction, a Sudoku, was mathematical in nature, as compared to the language-based study. By having the 
distraction in place, participants didn't merely recall the information from the story, but had to analyze the message on some cognitive level in order for them to discuss them in their answer.

Participants' open-ended responses were coded by two undergraduate students blind to the participants' condition. The coders looked at whether participants talked about the issues of health care, immigration, or offshore drilling. The coders also analyzed each answer for attributes associated with those issues. With health care, coders analyzed whether participants talked about the senator's plan regarding citizens needing health care, the senator's plan regarding companies providing health care, the senator's arguing against the government providing health care, or the specific sources discussed in the story. Coders analyzed the immigration story to determine if participants talked about the senator's immigration policy, the senator's issues regarding illegal immigration, the senator's plan to integrate immigrants into our culture, the specific sources discussing why immigrants fled their country, or the specific sources discussed in the article. The coders analyzed the offshore drilling responses to determine whether participants discussed the senator's feelings on the energy crisis, the senator's feelings on the U.S. dependency on oil, the senator's plan to drill along the Gulf Coast, the senator's arguing about needing more drilling to combat rising gas prices, or the specific sources concerns regarding environmental issues associated with offshore drilling. Coders analyzed each openended response to determine if the participants wrote about the attributes associated with the issue $(0=$ no, $1=$ yes $)$. The number of "yes" responses were summed together to determine how many attributes each participant used when discussing the issues. All of the coders' yes/no responses were analyzed for intercoder reliability using a macro in SPSS to gauge Krippendorff's alpha (Hayes, \& Krippendorff, 2007). The coefficients showed that the measures were coded reliably, with alpha levels associated above .80 .

\section{Control Variables}

Participants answered several demographic variables to control for in the final analysis. Participants used a 5-point scale to indicate their level of education from less than high school to graduate work. Participants also used a 5-point scale to indicate their level of income, ranging from less than $\$ 30,000$ to more than $\$ 100,000$. Gender was coded with 0 being male and 1 being 
female. Participants used a 6-point scale to indicate their race, but the variable was dummy coded into a new variable. Caucasians were coded as 1 while all other races became 0 . Participants also indicated the year they were born. The data were recoded into a new variable taking the current year minus the year of birth to obtain an age. Besides these basic demographic variables, the study investigated the participants' political leanings, including asking their political party affiliation. Political party affiliation was recoded into two dummy variables with Republican coded as 1 / others coded as 0 and Democrats coders as 1/others coded as 0 . Political strength was indicated by a 5-point scale with strongly conservative (1) to strongly liberal (5). All of the continuous variables, including the demographic variables and the dependent variables, were centered (Aiken \& West, 1991). The variables were centered for analysis because the parameters were more easily interpreted. Also, centering the variables helped to control for issues such as multicollinearity.

\section{Results}

\section{Preliminary Analysis}

The findings indicated that those who were exposed to health care $(t(190)=8.81, p<.001)$, immigration $(t(190)=6.40, p<.001)$, or offshore drilling $(t(190)=5.33, p<.001)$ cited the attributes of the issues more than those who were exposed to the other two issues. Therefore, the study concluded an agenda-setting effect in that participants cited attributes of issues they were exposed to, indicating they would share those attributes with friends.

\section{Main Analysis}

To test the three hypotheses, the study used $t$-test analyses to determine whether participants cited the attributes associated with the issue more when they were exposed to that issue as compared to those who were exposed to the other two issues. To answer the research question, the study used $t$-test analyses to determine whether participants cited the attributes associated with the issue more when they were exposed to the conventional news story or the humorous news story. All three issues were combined for analyses. To better explain the results, the final analysis included hierarchical linear regression to take into account control variables that might have had an effect on the number of attributes cited by participants. 
The results indicated those who received the issue cited the attributes of those issues - health care, $t(95)=5.79, p<.001$; immigration $t(95)=6.08, p<.001$; and offshore drilling $t(95)=$ $4.83, p<.001$. The results indicated support for the first hypothesis in that those participants who received the conventional news cited attributes of issue they were exposed to as compared to those participants who were exposed to the other two issues. The findings indicated participants accepted the attributes of the issue when they received the humorous news as well - health care $t(93)=6.70, p<.001$; immigration $t(93)=3.02, p<.001$; and offshore drilling $t(93)=2.78, p<$ .001. The results indicated support for the second hypothesis in that participants who were exposed to the humorous news cited attributes of the issue as compared to those participants were exposed to the other two issues.

With regard to the research question, the results showed that participants who were exposed to the health care and offshore drilling stories showed no significant difference between the two conditions regarding the number of attributes used when discussing those issues, $t(59)=.26, p=$ .794 and $t(59)=1.73, p=.088$, respectively. However, the results showed that those participants who were exposed to the conventional immigration news story cited more attributes of that issue as compared to those who were exposed to the humorous immigration news story, $t(68)=2.07, p$ $<.05$. When all three issues were analyzed together, the data indicated a significant difference in the number of attributes participants cited depending on which condition they received. Participants who were exposed to the conventional news cited more attributes of the issue as compared to those who were exposed to the humorous news, $t(190)=2.34, p<.05$.

A hierarchical multiple linear regression analysis was performed to evaluate how well the key variables predicted the number of attributes participants cited when they were asked what they might tell a friend about a certain issue, taking into account several control variables. Demographic variables were entered in the first block of the regression model, with the type of program, either conventional or humorous news, entered in the second block of the regression model. All three issues were combined for the regression analysis. The findings indicated participants appeared to cite the attributes of the issues more when they were exposed to the conventional news story as compared to the humorous news story, answering the research 
question. Of the demographic variables, only the age of the participants explained the dependent variable $(B=-.24, p<.05)$, with younger participants citing more attributes of an issue as compared to older participants. The first model had an Adj. $R^{2}=.04(F(8,183)=1.93, p=.058$ versus the second model $A d j . R^{2}=.06(F(9,182)=2.26, p<.05$. The complete model explained $10 \%$ of the variance associated with the dependent variable, $R^{2}=.10, F(1)=4.59, p<.05$.

\section{Discussion}

The results showed conventional news and humorous news both could affect public opinion formation by influencing the number of attributes cited about the issues citizens received. Although both could influence public opinion, conventional news had more influence on the second-level agenda-setting effects than the humorous news.

When exposed to an issue, citizens cited the attributes of the issues they received more than those who received the other two issues. The findings were consistent with other studies (Dearing \& Rogers, 1996; McCombs, 2004). As these previous scholars have indicated, conventional news often sets the agenda. That means conventional news often transfer the salience of issues, or attributes associated with those issues, from the media's agenda to citizens' agenda. For example, those citizens who were exposed to the health care news story cited more of the attributes associated with the health care story than those who were not exposed to the health care story. The conventional news could affect the transfer of attribute salience from the media's agenda to citizen's agenda.

Scholars also have indicated that humorous information could affect public opinion (Polk et al., 2007; Holbert et al., 2009; Morris, 2009), which is similar to the findings in this study. Those exposed to the humorous news cited the attributes of the issue more as compared to those participants who were exposed to the other issues. Priming research has shown that entertainment programs could prime citizens in their overall evaluation of their leaders (Moy et all, 2005). Scholars have argued priming is an extension of agenda setting - especially secondlevel agenda setting - because both theories rely on the accessibility of issues in memory. 
Therefore, since scholars have seen these programs influence the priming effects, one could assume the programs might influence second-level agenda-setting effects.

The findings indicated that conventional news appeared to influence the second-level agendasetting effects more so than did the humorous news. Although both conventional news and humorous news affected the transfer of attribute salience, citizens who received the conventional news cited more attributes of the issues they received as compared to the number of attributes cited by those who received the humorous news. So although the attributes appeared accessible in memory, other cognitive mechanisms might be at play here with regards to conventional news versus humorous news. Scholars have argued that citizens must consider an issue important for them to cite the issue as a major problem facing the nation (Dearing \& Rogers, 1996; McCombs, 2004). The results from this study corroborate this view.

Citizens who heard a conventional news story saw the issue as more problematic in society than those who heard a humorous news story. Citizens may have dismissed the issue more when presented as a humorous news story as compared to a conventional news story; therefore, they dismissed the attributes of the issue when that issue was presented as a humorous news story as compared to a conventional news story (Nabi et al., 2007). Scholars also have argued not all humor is the same. The humor in this study might equate more to horatian humor, or humor witty and light, not the biting satire of juvenalian satire. Scholars have shown citizens did not see the lighter humor to contain message strength or influence on self (Holbert et al., 2011; Holbert et al., 2013). Therefore, citizens did not accept the attributes of the message when the message was presented with witty or light humor as much as they did conventional news in regards to this study. They discounted the seriousness of messages. And often for citizens to be impacted by agenda-setting effects, citizens must feel the salience of the issue as having issue importance. In this case, they might have discounted the importance of the issue because of the humor.

Despite the promising findings here, the study had several limitations. One limitation was using an experiment to show an agenda-setting effect. Agenda setting often takes time to transfer attribute salience from the media's agenda to the public's agenda. Because of this, the researcher 
used issues already prevalent in the media. A second limitation was using radio addresses rather than television programs. The findings cannot be specified to television news programs, such as The Daily Show or The Colbert Report. However, the findings are important to understand the impact humorous messages might have on agenda-setting effects.

\section{Conclusion}

The findings showed promise in that both conventional and humorous showed a second-level agenda-setting effect. More studies need to investigate how different structures of information influence agenda setting. More studies also need to investigate how different types of humor might relate to second-level agenda setting. However, the results here further the current discussion into agenda-setting effects by showing, despite citizens turning to other programs for information, conventional news shows are more successful in influencing the second-level agenda-setting effect. In other words, conventional news programs appear to create "the pictures in our heads" more than the humorous news shows. 


\section{Reference}

Aiken, L. S., \& West, S. G. (1991). Multiple Regression: Testing and interpreting interactions . Newbury Park, CA: Sage.

Althaus, S. L., \& Tewksbury, D. (2002). Agenda setting and the 'new' news: Patterns of issue importance among readers of the paper and online versions of the New York Times. Communication Research, 29, 180-207.

Baumgartner, J.C., \& Morris, J. S. (2006). The Daily Show effect: Candidate evaluations, efficacy, and American youth. American Politics Research, 34, 341-367.

Dearing J. W. \& Rogers E. M. (1996). Agenda-Setting. Thousand Oaks, Ca: Sage Publications.

Evatt, D., \& Ghanem, S. (2001). Building a scale to measure salience. Paper presented to the World Association for Public Opinion Research, Rome, Italy.

Hayes, A. F., \& Krippendorff, K. (2007). Answering the call for a standard reliability measure for coding data. Communication Methods and Measures, 1, 77-89.

Holbert, L. R., Hmielowski, J., Jain, P., Lather, J., \& Morey, A. (2011). Adding nuance to the study of political humor effects: Experimental research on juvenalian satire versus horatian satire. American Behaviaoral Scientist, 55, 187-211.

Holbert, R. L., Lambe, J. L., Dudo, A. D., \& Carlton, K. A. (2007). Primacy effects of The Daily Show and National TV News Viewing: Young viewers, political gratifications, and internal political self-efficacy. Journal of Broadcasting \& Electronic Media, 51, 20-38.

Holbert, R. L., Tchernev, J. M., Walther, W. O., Esralew, S. E., \& Benski, K. (2013). Young voter perceptions of political satire as persuasion: a focus on perceived influence, persuasive intent, and message strength. Journal of Broadcasting \& Electronic Media, 57, 170-186.

Iyengar, S., \& Kinder, D. R. (1986). More than meets the eye: TV news, priming, and public evaluations of the president. In G. Comstock (Ed.) Public Communication and Behavior, Volume 1 (pp. 135-163). Syracuse, New York: Academic Press, Inc.

Iyengar, S., \& Kinder, D. R. (1987). News that matters: Television and American opinion. Chicago: The University of Chicago Press. 
Kohut, A. (2007 April 15). What Americans Know: 1989-2007: Public Knowledge of Current Affairs Little Changed by News and Information. Retrieved from http://peoplepress.org/reports/display.php3?ReportID=319 on March 1, 2008.

Kolbert, E. (2004, April 19). Stooping to conquer: Why candidates need to make fun of themselves. The New Yorker.

Kowalewski, J. (2013). "It's Not Just a Laughing Matter: How Entertainment News Programs Influence the Transfer of the Media's Agenda to the Public's Agenda Similarly to Traditional Hard News.” In T. Johnson (eds.) Agenda Setting in a 2.0 World: New Agendas in Communication (New York, N.Y.: Routlege).

Kowalewski, J. (2013). "Does Humor Matter? An Analysis of How Hard News versus Entertainment News Styles Influence the Agenda-Setting Effects" Southwestern Mass Communication Journal.

Kowalewski, J., \& Stewart, D. (2013). “To Laugh or Not to Laugh: How Different Versions of News Stories Interact with Cynicism and Efficacy to Impact Individuals' Acceptance of the Media Agenda." Southwestern Mass Communication Journal.

Lippmann, W. (1922). Public Opinion. New York: Harcourt Brace.

McCombs, M. (2004). Setting the agenda: The mass media and public opinion. Cambridge, England: Polity Press.

McCombs, M. (2005). A look at agenda-setting: Past, present and future. Journalism Studies, 6(4), 543-557.

McCombs, M., Llama, J. P., \& Lopez-Escobar, E. (2000). Setting the agenda of attributes in the 1996 Spanish general election. Journal of Communication, 77-92.

McCombs, M., Llama, J. P., Lopez-Escobar, E., \& Rey, F. (1997). Candidate images in Spanish elections: Second-level agenda-setting effects. Journalism \& Mass Communication Quarterly, 74(4), 703-717.

McCombs, M. E., \& Shaw, D. L. (1972). The agenda-setting function of mass media. Public Opinion Quarterly, 36(2), 176-187.

Miller, J. M. (2007). Examining the mediators of agenda setting: A new experimental paradigm reveals the role of emotions. Political Psychology, 28(6), 689-717. 
Miller, J. M., \& Krosnick, J. A. (2000). News media impact on the ingredients of presidential evaluations: Politically knowledgeable are guided by a trusted source. American Journal of Political Science 44(2), 301-315.

Morris, J. S. (2009). The Daily Show with Jon Stewart and audience attitude change during the 2004 party convention. Political Behavior, 31, 79-102.

Moy, P., Xenos, M. A., \& Hess, V. K. (2006). Priming Effects of Late-Night Comedy. International Journal of Public Opinion Research, 18(2), 198-210.

Nabi, R.L., Moyer-Gusé, E., \& Byrne, S. (2007). All joking aside: A serious investigation into the persuasive effect of funny social issue messages. Communication Monographs, 74(1), 29-54.

Polk, J., Young, D. G., Holbert, R. L. (2009). Humor complexity and political influence: An elaboration likelihood approach the effects of humor type in The Daily Show with Jon Stewart. Atlantic Journal of Communication, 17, 202-219.

Roskos-Ewoldsen, D. R., Klinger, M. R., \&Roskos-Ewoldsen, B. (2007). Media Priming: A Meta-Analysis. In R. W. Priess, B. M. Gayle, N. Burrell, M. Allen, \& J. Bryant (Eds.), Mass media effects research: Advances through meta-analysis. (pp. 53-80). Mahwah, New Jersey: Lawrence Erlbaum Associates, Inc.

Scheufele, D. A. (2000). Agenda-setting, priming, and framing revisited: Another look at cognitive effects of political communication. Mass Communication \& Society 3(2\&3), 297-316.

Scheufele, D. A., \& Tewksbury, D. (2007). Framing, agenda setting, and priming: The evolution of three media effects models. Journal of Communication 57, 9-20. Wanta, W. (Spring 1988). The effects of dominant photographs: An agenda-setting experiment. Journalism Quarterly, 65(1), 107-111.

Wanta, W., \& Ghanem, S. (2007). Effects of Agenda Setting. In R. W. Priess, B. M. Gayle, N. Burrell, M. Allen, \& J. Bryant (Eds.), Mass media effects research: Advances through meta-analysis. (pp. 37-52). Mahwah, New Jersey: Lawrence Erlbaum Associates, Inc.

Weaver, D. (1994). Media agenda setting and elections: Voter involvement or alienation? Political Communication, 11, 347-356. 
Young, D., Hoffman, L. (2009). An Experimental Exploration of Political Knowledge Acquisition from the Daily Show Versus CNN Student News. APSA 2009 Toronto Meeting. Social Science Research Network, retrieved from http://papers.ssrn.com/sol3/papers.cfm?abstract_id=1451400

Zillmann, D. (2000). Humor and Comedy. In D. Zillmann, \& P. Vorderer (Eds.), Media Entertainment: The Psychology of its Appeal (pp. 37-58). Mahwah, New Jersey: Lawrence Erlbaum Associates, Inc.

Zillmann, D., Taylor, K., \& Lewis, K. (Spring 1998). News as nonfiction theater: How dispositions toward the public cast of characters affect reactions. Journal of Broadcasting \& Electronic Media, 42(2), 153-170. 